\title{
The Risk of Water, Energy, and Food Nexus under Regional Metabolism for Multi-Sector City
}

\author{
I-Chun Chen \\ Department of Land Resources, Chinese Culture University, Taiwan \\ Email: cyj25@ulive.pccu.edu.tw
}

How to cite this paper: Chen, I-C. (2020) The Risk of Water, Energy, and Food Nexus under Regional Metabolism for Multi-Sector City. Journal of Environmental Protection, 11, 909-920. https://doi.org/10.4236/jep.2020.1110057

Received: September 26, 2020

Accepted: October 25, 2020

Published: October 28, 2020

Copyright (อ 2020 by author(s) and Scientific Research Publishing Inc. This work is licensed under the Creative Commons Attribution International License (CC BY 4.0).

http://creativecommons.org/licenses/by/4.0/

\section{(c) (i) Open Access}

\begin{abstract}
The Urban Nexus system creates another risk characteristic of resource metabolism. Urban metabolism has complex effects from multi-levels and multi-sectors resulted from the changes socio-economic. It is crucial to implement effective urban governance; in particular, resource metabolism creates a new nexus risk by dramatic growth in urban areas. The resource metabolism associates with water, energy, and food consumption on an urban scale that drives the intensity in resource metabolism. Therefore, this study estimates the FEW intensity of the nexus and demand side in material flow analysis by organizing into four categories of resource metabolism, including supply side, process side, demand side, and final sink. This research compares different characteristics for a small island dominated by tourism and a multi-sector city dominated by increasing economic activity. The resource intensity on the demand side and resource service systems are evaluated to identify the nexus intensity and risk for FEW nexus at the urban scale. This study determines that constraints for resource service systems are complex, and suggests that resource consumption intensity is higher in that particular nexus and demand sector. To avoid excessive loads on resource metabolism, sustainable resource management should implement trade-off strategies after analyzing the resource metabolism for urban nexus.
\end{abstract}

\section{Keywords}

Nexus Risk, FEW, Resource Metabolism, Multi-Sector City

\section{Introduction}

With the dramatic growth in urban areas around the world, new methods of evaluating risks to resources are currently being developed. Resource metabol- 
ism forms a nexus of resource flows because demands on one resource can intensify the stress on the supply of other resources. Therefore, it is crucial to couple the management of multiple resources in the pursuit of urban sustainability. Regional resource metabolism analysis describes the relationship between resource efficiency and socio-economic activities on the demand side, including production and consumption, land use, form and function, population dynamics, technology, and economic values of industrial sectors [1]. International non-profit organizations have used resource analysis with a radar chart to explain the index of resource security in urban areas [2] [3] and more researchers have advanced the optimization analysis of cities that are water supply-sensitive [4] [5] [6]. However, in the regional food, energy, and water nexus (FEW nexus) risk assessment, we need to review the system qualitative and quantitative data and to establish a resource flow model, then select the supply and demand risk factor to give the future scenario prediction.

Given that resource metabolism differs from resource to resource, the intensity of resource use is a function of the urban area's infrastructure patterns and demand sectors. The resource intensity of sectors engage in the nexus in urban systems is an important force that drives resource metabolism, and constraints are more obvious due to specific characteristics associated with any particular city [7] [8] [9]. Therefore, resource intensity patterns should be identified and evaluated at an urban scale, particularly in regions with extremely high levels of urban growth and limited resource supplies [10] [11] [12]. The intensity factor of FEW nexus can be derived from the local influencing factor including energy consumption data on water service infrastructure, water consumption data on energy service infrastructure, energy and water consumption on the demand side, energy and water consumption per area in industry or commercial sectors, and food intensity per farmland area, among others. This reveals the coupling of complex nexuses at an urban scale and facilitates the development of flexible solutions that improve the resilience of a city [4] [13] [14]. More research is needed to identify the vulnerability created by higher demands on livelihoods under regional constraints before considering trade-off strategies for FEW nexus in the future [1] [15] [16] [17] [18].

This study examines the characteristics of resource flows and methodologies based on the principle of mass balance in material flow analysis. In addition, resource input and output databases are established at an urban scale to analyze the resource risk associated with the FEW nexus. This study also discusses the resource nexus between two cities and compares resource consumption intensity and resource supply-demand risk to propose effective adaptive strategies.

\section{Material and Methods}

In this study, a suitable approach is first determined to analyze the risk associated with the FEW nexus at the urban scale. We can calculate the flow of the FEW nexus in terms of sectors to quantify the linkage between different subsys- 
tems, as shown in Figure 1. FEW demands associated with residential, commercial, and industrial institutions as well as agriculture are utilized to develop the characteristics associated with different urban sectors. Based on the analysis framework, the hotspots of nexus risk can be identified, and adaptive strategies can be developed and assessed. Figure 2 illustrates the risk analysis of FEW nexus in this study. First step: in the FEW nexus resource flow system, the interlinkage relationship is to be able to make water, energy and grain three subsystems link together, including water-energy intertwined, water-food intertwined, energy-food intertwined, energy-water and intertwined food-energy intertwined. Second step: to establish FEW Nexus system, the quantitative analysis of intertwined nodes is a very important step, by inventory local water resources, energy and food supply system quantitative understanding local citizens' habits and go

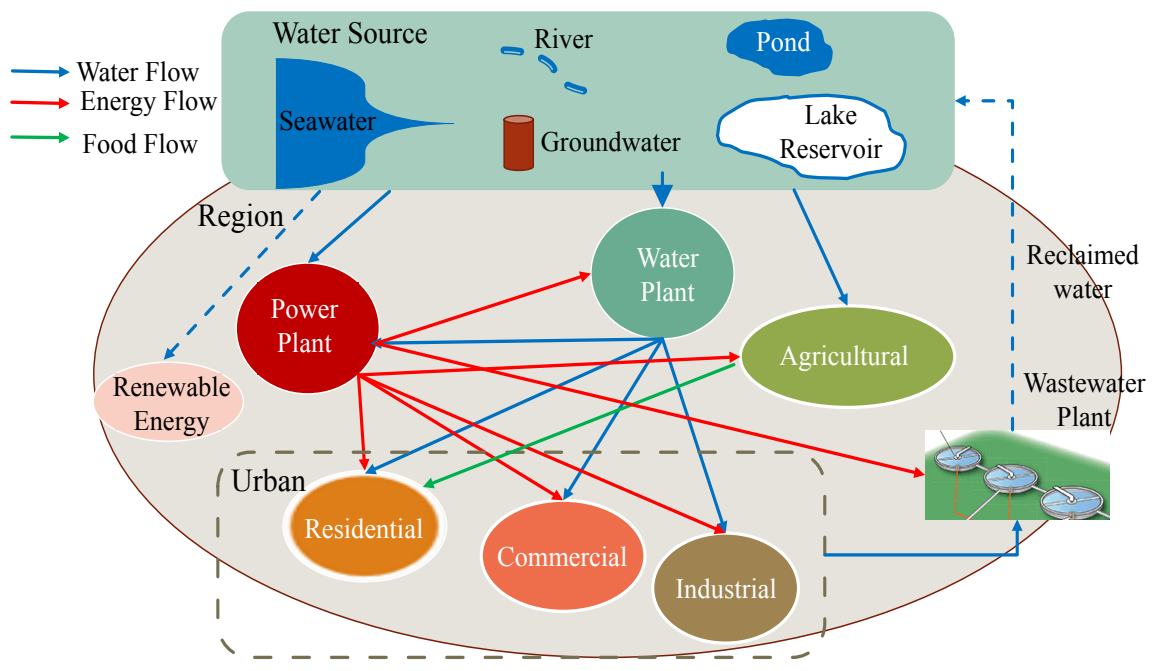

Figure 1. Conceptual framework of resources metabolism index and nexus nodes in this study. Note: The blue line shows water metabolism indicating water flows sectors. Red line shows energy metabolism indicating energy flows sectors. The green line shows food metabolism indicating food flows sectors.

\section{Step 4}

To descript the risk characterization

- Risk of FEW Nexus

- Adaptive opportunity

Step 3

To quantify the risk and changes

- Baseline risk

- Incremental risk

\section{Step 1}

To establish FEW Nexus system

- Scope definition

- Nexus definition

Step 2

To analyze intensity and resource flow

- Supply- demand flow analysis

Figure 2. The research flow chart. 
risk analysis to have more detailed discussion. It is important to identify the number and types of factors that affect water, energy, and food intensity at different nexus nodes in the studied city to properly quantify the resource flows. If an area has seawater desalination facilities or reclaimed water recycling facilities, the nexus aspect must also be considered because these types of water production processes have an intertwined energy-water relationship, identified impact factor and intensity data to each resource for the different metabolism node in nexus stage. Third step: to analyze the intertwined node coefficients into the inventory system and link the three resources systems of water, energy and food nexus. In the case of a single resource change, the risk of the other resource systems will be the effect. This study can illustrate the balance of resource flows in each flow, and then visualize the loss and stock of the material metabolism in each stage by using e!Sankey. When the "supply-demand risk for FEW nexus" of resources was less than Secure Supply ( $\mathrm{Ri}$ is less than 100), the security of resources in relation to supply and demand are considered to be under stable conditions. If the $\mathrm{Ri}$ is greater than 100, the resources are in a high-risk state and are considered insecure, which can destroy local resources in the long term. Four step: sustainable resource management should consider and implement trade-off strategies based on the analysis of resource metabolism with conceptual modeling for urban nexus.

This research compares different characteristics for a small island dominated by tourism (Kinmen Island) and a multi-sector city dominated by increasing economic activity (Taichung City). Kinmen Island locates on the east side of China and on the west side of Taiwan. It is a famous national park in Taiwan. Kinmen City is an independent island with an area of $151.656 \mathrm{~km}^{2}$. Slowing population growth for the resident population after 2019; in contrast, the tourist population of Kinmen Island increases year by year. The main industry in Kinmen Island is food processing and the main agricultural products are beef, sorghum bicolor, and wheat; more than $90 \%$ of the produce is used for tourist consumption. Due to the shortage of water supply in Kinmen, the big problem of water management needs to solve for the local government now. The Taichung Metropolitan Area is the second largest metropolitan area in Taiwan, with a total area of $2215 \mathrm{~km}^{2}$ and a population of 2.77 million. With Foreign Trade rapid development, Taichung's industries gradually changed from agriculture to commercial and industrial city.

\section{Results and Discussion}

\subsection{Intensity of Urban Metabolism}

The resource use intensity in the urban area can also represent the resource intensity of urban metabolism. A higher value for a particular process indicates that the resource consumption intensity is higher. Resource consumption in the residential, industrial, commercial, and agricultural sectors in Kinmen Island and Taichung City are presented in Table 1 . In the residential sector, the intensity 
Table 1. Resource consumption intensity of water, food and energy in different department in Kinmen Island and Taichung City.

\begin{tabular}{|c|c|c|c|c|c|c|c|}
\hline \multirow{2}{*}{ Department } & \multirow{2}{*}{ Sub-Items } & \multicolumn{3}{|c|}{ Taichung } & \multicolumn{3}{|c|}{ Kinmen } \\
\hline & & Water & Food & Energy & Water & Food & Energy \\
\hline \multirow[t]{7}{*}{ Residential } & & $273.00^{\mathrm{a}}$ & $86.58^{\mathrm{f}}$ & $13,586.94^{\mathrm{h}}$ & $117.00^{\mathrm{a}}$ & $86.58^{\mathrm{f}}$ & $746,023.67^{\mathrm{h}}$ \\
\hline & Manufacture of Food Products and Beverages & $0.19^{\mathrm{b}}$ & $0.18^{\mathrm{g}}$ & $13,609.57^{\mathrm{i}}$ & $0.09^{\mathrm{b}}$ & $4.41^{\mathrm{g}}$ & $90.25^{\mathrm{i}}$ \\
\hline & Manufacture of Textiles & $0.21^{\mathrm{b}}$ & & $7945.95^{\mathrm{i}}$ & $0.00^{\mathrm{b}}$ & & $0.00^{\mathrm{i}}$ \\
\hline & Manufacture of Furniture & $0.01^{\mathrm{b}}$ & & $5834.89^{\mathrm{i}}$ & $0.00^{\mathrm{b}}$ & & $0.17^{\mathrm{i}}$ \\
\hline & Manufacture of Pulp and Other Paper Products & $0.29^{\mathrm{b}}$ & & $7210.34^{\mathrm{i}}$ & $0.00^{\mathrm{b}}$ & & $0.03^{\mathrm{i}}$ \\
\hline & Manufacture of Chemical Products & $0.09^{\mathrm{b}}$ & & $8483.31^{\mathrm{i}}$ & $0.00^{\mathrm{b}}$ & & $0.17^{\mathrm{i}}$ \\
\hline & Manufacture of Basic Metals and Metal Products & $0.08^{\mathrm{b}}$ & & $57,891.07^{\mathrm{i}}$ & $0.00^{\mathrm{b}}$ & & $4.05^{\mathrm{i}}$ \\
\hline \multirow[t]{7}{*}{ Industrial } & $\begin{array}{l}\text { Manufacture of Computers, Electronic Optical } \\
\text { Products and Transportation }\end{array}$ & $0.12^{\mathrm{b}}$ & & $15,091.55^{\mathrm{i}}$ & $0.09^{\mathrm{b}}$ & & $0.00^{\mathrm{i}}$ \\
\hline & Printing and Service Activities Related to Printing & $0.01^{\mathrm{b}}$ & & $1734.82^{\mathrm{i}}$ & $0.00^{\mathrm{b}}$ & & $1.24^{\mathrm{i}}$ \\
\hline & Manufacture of Chemical Material & $0.26^{\mathrm{b}}$ & & $16,639.62^{\mathrm{i}}$ & $0.03^{\mathrm{b}}$ & & $0.17^{\mathrm{i}}$ \\
\hline & Manufacture of Non-metallic Mineral Products & $0.03^{\mathrm{b}}$ & & $9685.48^{\mathrm{i}}$ & $0.00^{\mathrm{b}}$ & & $23.86^{\mathrm{i}}$ \\
\hline & Manufacture of General-purpose Machinery & $0.06^{\mathrm{b}}$ & & $33,548.92^{\mathrm{i}}$ & $0.00^{\mathrm{b}}$ & & $0.10^{\mathrm{i}}$ \\
\hline & $\begin{array}{l}\text { Manufacture of Other Fabricated Metal and } \\
\text { Non-metallic Products }\end{array}$ & $0.08^{\mathrm{b}}$ & & $2774.50^{\mathrm{i}}$ & $0.00^{\mathrm{b}}$ & & $0.00^{\mathrm{i}}$ \\
\hline & $\begin{array}{l}\text { Manufacture of Material Medicines, Petroleum } \\
\text { and Coal Products }\end{array}$ & $0.11^{\mathrm{b}}$ & & $5638.01^{\mathrm{i}}$ & $0.00^{\mathrm{b}}$ & & $0.00^{\mathrm{i}}$ \\
\hline \multirow[t]{3}{*}{ Commercial } & & $2.36^{\mathrm{c}}$ & & $265,312.71^{j}$ & $22.91^{c}$ & & $33,593,600.00^{j}$ \\
\hline & Corn & $15,261.90^{\mathrm{d}}$ & & $17,676.12^{\mathrm{k}}$ & $3.23^{\mathrm{d}}$ & & $0.00^{\mathrm{k}}$ \\
\hline & Vegetable & $8346.33^{\mathrm{d}}$ & & & $0.00^{\mathrm{d}}$ & & \\
\hline \multirow{2}{*}{ Agricultural } & Other & $3544.18^{\mathrm{d}}$ & & & $0.00^{\mathrm{d}}$ & & \\
\hline & Livestock & $4,767,244.27^{e}$ & & $744,999.57^{1}$ & $6,617,790.23^{\mathrm{e}}$ & & $0.00^{1}$ \\
\hline
\end{tabular}

Unit: a. L/day cap.; b. Million $\mathrm{m}^{3} / \mathrm{ha}$ (industry land use area); c. $\mathrm{m}^{3} /$ year cap.; $\mathrm{d} . \mathrm{m}^{3} / \mathrm{m}^{2} /$ year; e. $\mathrm{m}^{3} / \mathrm{year} /$ per ton meat; f. $\mathrm{Kg} / \mathrm{year}$ cap.; g. Kg/m² (industry land use area); h. KWh/year cap.

of water consumption in Taichung City is higher than that in Kinmen Island. However, with respect to energy consumption, Kinmen Island's energy consumption intensity is five times greater than that of Taichung City. In the industrial sector, different kinds of industries are categorized. The resource consumption intensities are different in different types of industries. Taichung City has many more types of industries than Kinmen Island. The main industry in Kinmen Island is food processing. Thus, the highest industrial water consumption in Kinmen is associated with the production of food and beverage products and the manufacture of transportation vehicles. These two industries are also the largest consumers of energy. With respect to food consumption, the food production industry is the only one that requires food to produce its products, making it the only industry that consumes all three types of resources. In Taichung City, the industrial sector has many more types of industries than Kinmen Island. The primary industry in Taichung City is computer manufacturing and 
electronic optical product manufacturing. The highest energy resource consumption intensity is associated with the production of basic metals and general-purpose machinery. In short, the production of food products and beverages in Kinmen Island results in a higher food consumption intensity, but the water and energy consumption intensity are higher in Taichung City. The resource consumption intensity in the commercial sector suggests that energy and water consumption intensities in Kinmen Island are higher than those in Taichung City so the resource use efficiency in Kinmen Island is lower than that in Taichung City. Thus, Kinmen Island would benefit from efforts to improve efficiency in the commercial sector. On the other hand, the water consumption intensity in the agricultural sector is higher in Taichung City than in Kinmen Island. Based on the data compiled and evaluated in this study, the water resource consumption intensity in Taichung City is higher than that in Kinmen Island in the residential, industrial, and agricultural sectors. These results indicate that the resource consumption intensity in Taichung City is higher, which suggest that resource use efficiency is lower in general. However, Kinmen Island's resource use efficiency is lower in the commercial sector. These results tend to support the suggestion that the consumption intensity can vary, depending on the various urban characteristics of a city.

\subsection{Risk Assessment of FEW Results}

The results of risk assessment in supply and demand are presented in Figure 3 and Figure 4. After analyzing the supply and demand data, the risks to FEW are presented for both areas. The main risk to water resources in Kinmen Island is associated with household water use (residential sector), whereas the main risk

\section{Risk of FEW Nexus on Kinmen Island}

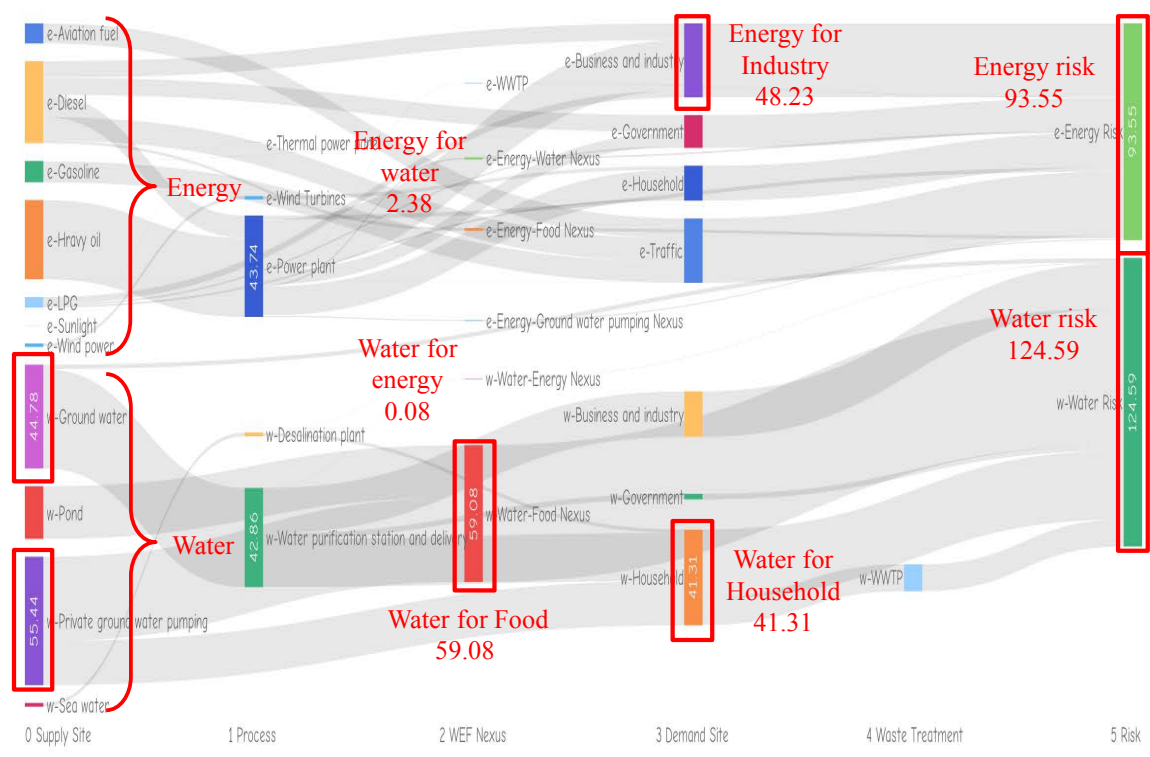

Figure 3. The risk of FEW nexus for Kinmen Island. 


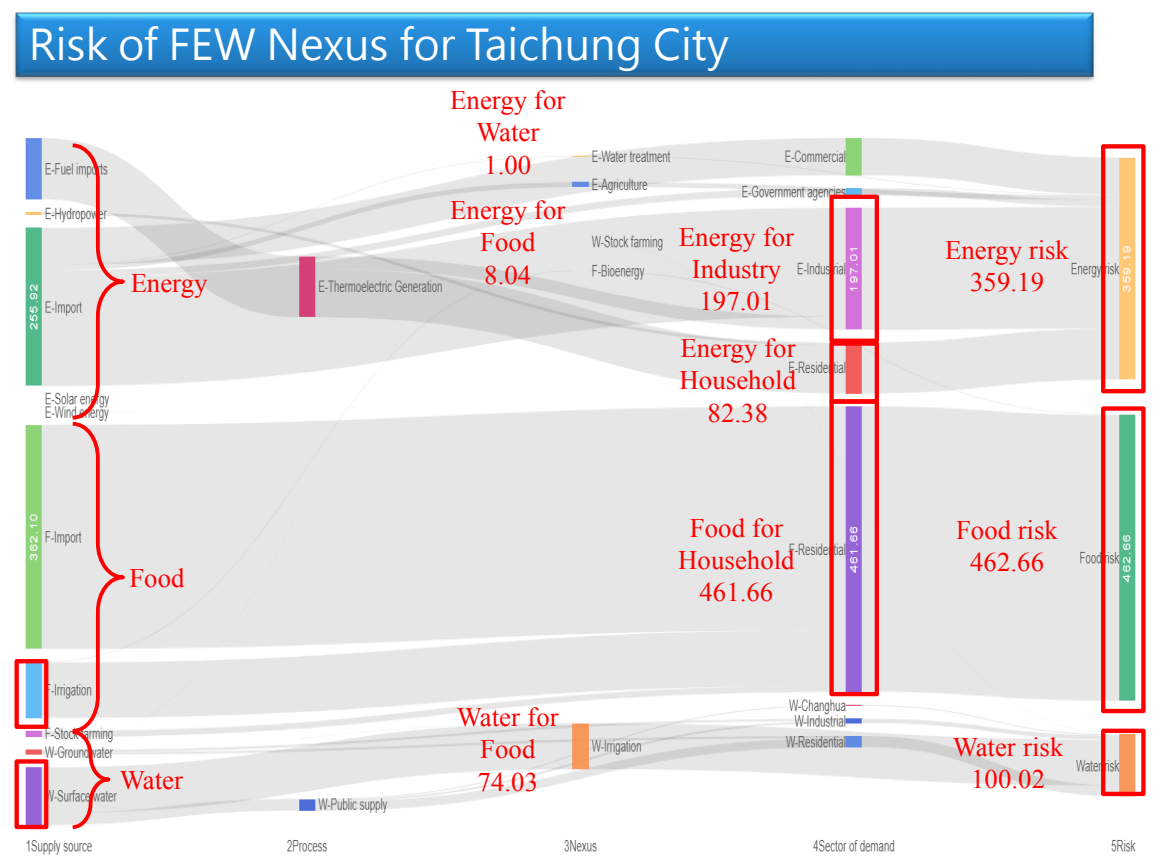

Figure 4. The risk of FEW nexus for Taichung City.

to energy resources is associated with the industrial sector. In Taichung City, the main energy risk is associated with the residential and industrial sectors, while the main food risk is associated with the residential sector. The food risk is relatively low in Kinmen Island, and the water risk is low in Taichung City. Most of the food is consumed in Kinmen Island, but fewer people live there; therefore, food consumption is lower than in Taichung City. On the other hand, the water resources of Taichung City are significantly larger than those of Kinmen Island, resulting in a lower water risk in Taichung City. For comparison, the total water risk is 124.59 and the energy risk is 93.55 in Kinmen Island, while the food risk is 462.55 and the energy risk is 359.19 in Taichung City.

According to the results, there are different risk issues associated with different areas. For example, the water demand risk is most serious in Kinmen Island, and new water resources are needed. Alternatively, water saving strategies can also be used to lower water risk. Food and energy resource demand risk is most serious in Taichung City. The total food consumption is much more in Taichung City than in Kinmen Island. Although food production is high in Taichung City, food consumption is also high. Thus, the food demand risk is highest among the three in FEW. Energy demand risk is also high in Taichung because the population is larger and there are more types of industries. To address the energy demand risk issue, both, the residential and industrial sectors, can implement energy-saving policies. These policies should connect with all sectors that influence risk. Thus, there would be much more efficient to decrease the FEW demand risk after analyzing the risks to FEW in different sectors.

The result shows in Figure 5 focus on the nexus risk between water, energy, and food. The risk of nexus means the effect of one resource consumption on 


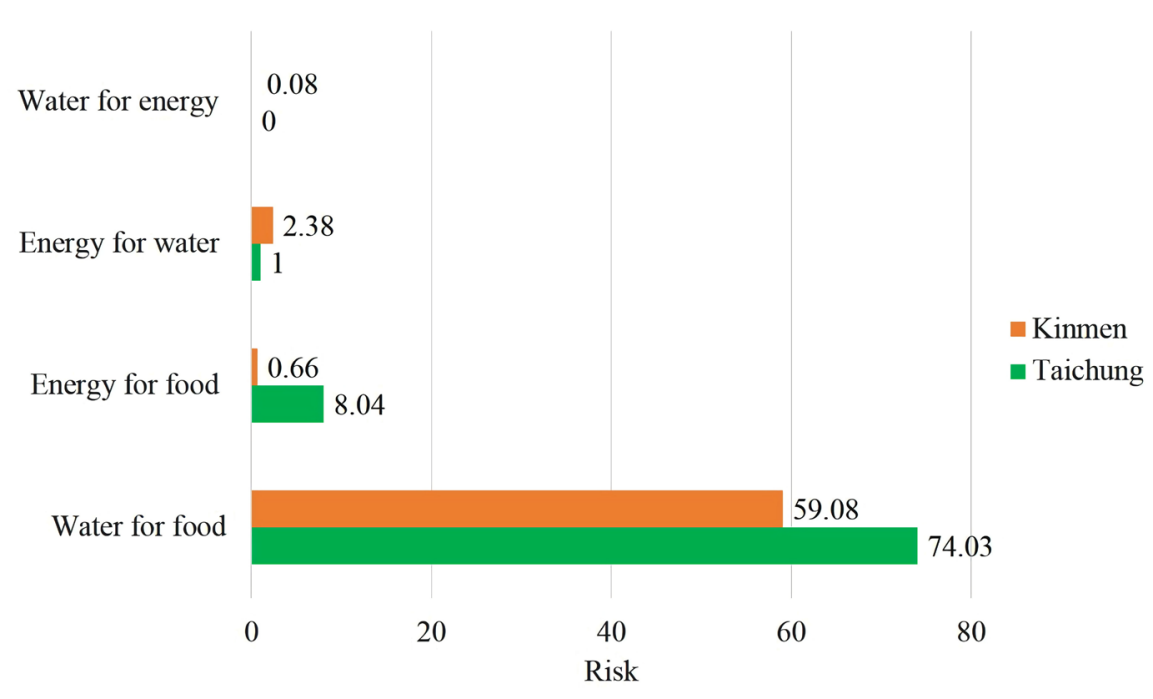

Figure 5. Comparing FEW nexus risk with Kinmen Island and Taichung City.

another resource consumption. Thus, a high food demand risk could indicate that the water demand risk is high since food production requires water. After calculating the risk for each sector and FEW nexus, the two areas show different nexus characteristics. The nexus risk in water for food is the highest in the two areas, where the driving factor mitigates nexus risk. On the other hand, water-for-food and energy-for-food risks in Taichung City are higher than those in Kinmen Island. Therefore, food security risk is quite important in Taichung City. Energy-for-water and water-for-energy risks in Kinmen Island are higher than those in Taichung City, because of the shortage of water and energy in Kinmen Island.

\subsection{Adaptation Strategies and Risk Changes}

According to the results, after analyzing the resource consumption intensity, a resource demand risk trend emerges. Policymakers should develop its policy after first understanding the resource consumption intensity. Therefore, this study considers the tradeoffs of FEW risks for supply and nexus strategies to assess the risk changes under three adaptive strategies on water supply for Kinmen Island and two adaptive strategies on food supply for Taichung City. We evaluate the changes of FEW risks in 2025 for business as usual (BAU) for Kinmen and Taichung City. The results present in Figure 6 and Figure 7. In Kinmen City, the results figure out that the water risk increases $12.8 \%$ and energy risk increase $6.2 \%$ at the same time. The result shows that energy risk increases the highest than another resource in 2025 for Taichung City. On the other hand, we although determine the mitigation solutions to food and water consumption but the risks of FEW nexus are still over the safety line in Taichung City. Even by conserving food and reducing food wastage, it would be difficult to reduce the food demand risk due to fast urban growth. We also understand that FEW nexus at the urban scale is overloading for resource supply if the urban growth continues fast in Taichung. On the contrary, water and energy risk all are decreased 


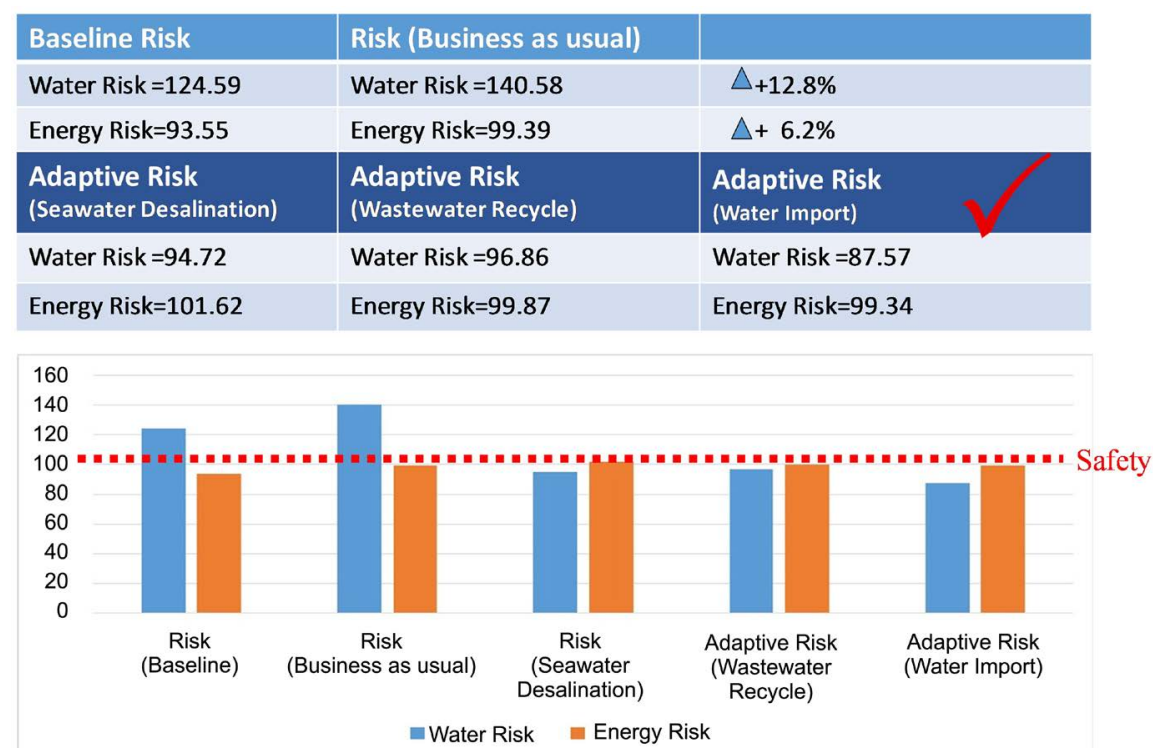

Figure 6. Risk changes after implementing the adaptive strategies in Kinmen Island.

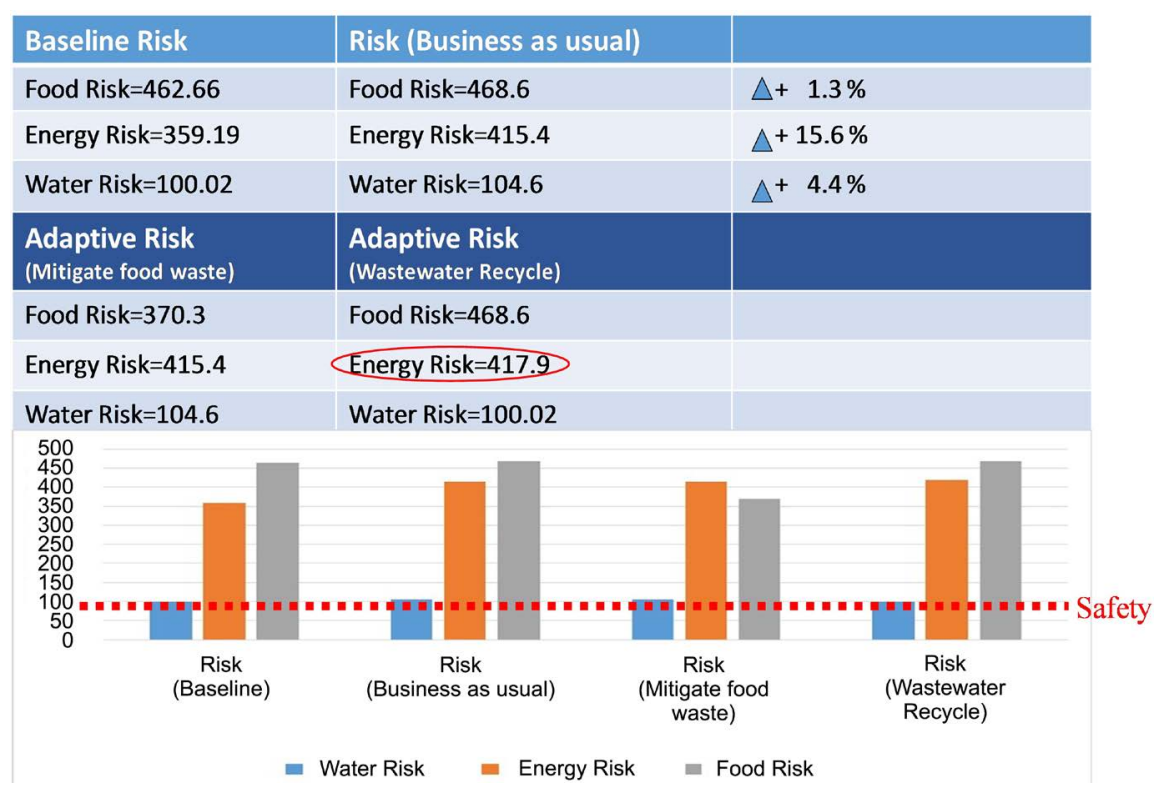

Figure 7. Risk changes after implementing the adaptive strategies in Taichung City.

under the safety line after implementing the adaptive strategies in Kinmen Island. Therefore, we understand that the effective solution for adapting the FEW risks after assessing resource metabolism.

\section{Conclusions}

According to the nexus risk at an urban scale, this study determines that constraints for resource service systems are complex, and higher risk suggests that resource consumption intensity is higher in that particular nexus process and demand sector. To improve resource self-sufficiency for each country, more diversity for resource supply is applied such as renewable energy and recycling 
water. Positive relationships are found between water/energy self-sufficiency and diversity in the Asia Pacific region [19]. As a result, the nexus risk for water and energy in resource governance should be more considered in the Asia Pacific region. For fast-growing cities, adjusting conditions and structures for single resource supply is ineffective in adapting the FEW risks. This research conducts a risk assessment for the FEW nexus on an urban scale toward a resilient city, under flexible resource metabolism. Different urban characteristics have different demand risk and nexus risk.

This research compares different characteristics for a small island dominated by tourism (Kinmen Island) and a multi-sector city dominated by increasing economic activity (Taichung City). In this study, the resource intensity (food, energy, and water) on the demand side and resource service systems are evaluated to identify the nexus intensity and risk for FEW nexus at the urban scale. Taichung City displays higher water and energy resource consumption intensity than Kinmen Island in the residential, industrial, and agricultural sectors. The results indicate that the resource consumption intensity of Taichung City is higher, which suggests that resource use efficiency is lower in general. In addition, due to the higher population density and diversity of the industrial sector in Taichung City than Kinmen Island, the resource consumption intensity and risk is much more than that in Kinmen Island. These results also indicate that a higher demand risk would lead to a higher nexus risk, particularly in Taichung City. In addition, this research explores more important in nexus risk for water and food in Taiwan, and nexus risk in Taiwan is not similar to a lower diversity of food in the USA, Canada, and Indonesia [19]. The nexus risk in water intensity for food is the highest in the two areas, where the driving factor strengthens the nexus risk. Significantly more efficiency would be necessary to decrease the FEW demand risk after analyzing the risk to FEW in different sectors. Based on the methodology of FEW nexus risk described in this study, we can redefine the requirement of fitting this objective such as water intensity and energy intensity including the nexus side of technology parameters.

\section{Acknowledgements}

This study was funded partially by the research project supported by the Ministry of Science and Technology (MOST105-2627-M-002 -038).

\section{Conflicts of Interest}

The author declares no conflicts of interest regarding the publication of this paper.

\section{References}

[1] Friis, C. and Nielsen, J.- $\varnothing$. (2014) Exploring the Potential of the Telecoupling Framework for Understanding Land Change. Transformations of Human-Environment Systems, Berlin.

[2] World Business Council for Sustainable Development (WBCSD) (2014) Co-Optimizing 
Solutions: Water and Energy for Food, Feeds and Fiber. Geneva.

[3] Food and Agriculture Organization (FAO) (2014) Walking the Nexus Talk: Assessing the Water-Energy-Food Nexus in the Context of the Sustainable Energy for All Initiative. Rome.

[4] Renouf, M.A., Kenway, S.J., Serrao-Neumann, S. and Low Choy, D. (2016) Urban Metabolism for Planning Water Sensitive Cities: Concept for an Urban Water Metabolism Evaluation Framework. Cooperative Research Centre for Water Sensitive Cities, Melbourne.

[5] Zeng, W., Wu, B. and Chai, Y. (2016) Dynamic Simulation of Urban Water Metabolism under Water Environmental Carrying Capacity Restrictions. Frontiers of Environmental Science \& Engineering, 10, 114-128.

https://doi.org/10.1007/s11783-014-0669-6

[6] Walker, R.V., Beck, M.B., Hall, J.W., Dawson, R.J. and Heidrich, O. (2014) The Energy-Water-Food Nexus: Strategic Analysis of Technologies for Transforming the Urban Metabolism. Journal of Environmental Management, 141, 104-115.

https://doi.org/10.1016/j.jenvman.2014.01.054

[7] Madrid-L'opez, C. (2014) The Water Metabolism of Socio-Ecosystems Epistemology, Methods and Applications. University Autonoma de Barcelona, Barcelona.

[8] Madrid-L'opez, C. and Giampietro, M. (2014) The Water Metabolism of Socio-Ecological Systems. Journal of Industrial Ecology, 19, 853-865.

https://doi.org/10.1111/jiec.12340

[9] Vanham, D. (2016) Does the Water Footprint Concept Provide Relevant Information to Address the Water-Food-Energy-Ecosystem Nexus? Ecosystem Services, 17, 298-307. https://doi.org/10.1016/j.ecoser.2015.08.003

[10] Asian Development Bank (ADB) (2012) Green Growth, Resources and Resilience Environmental Sustainability in Asia and the Pacific. Manila.

[11] Dodder, R.S., Barnwell, J.T. and Yelverton, W.H. (2016) Scenarios for Low Carbon and Low Water Electric Power Plant Operations: Implications for Upstream Water Use. Environmental Science \& Technology, 50, 11460-11470. https://doi.org/10.1021/acs.est.6b03048

[12] Chen, S. and Chen, B. (2016) Urban Energy-Water Nexus: A Network Perspective. Applied Energy, 184, 905-914. https://doi.org/10.1016/j.apenergy.2016.03.042

[13] Biggs, E.M., Bruce, E., Boruff, B., Duncan, J.M.A., Horsley, J., Pauli, N., McNeill, K., Neef, A., Ogtrop, F., Curnow, V.J., Haworth, B., Duce, S. and Imanari, Y. (2015) Sustainable Development and the Water-Energy-Food Nexus: A Perspective on Livelihoods. Environmental Science \& Policy, 54, 389-397.

https://doi.org/10.1016/j.envsci.2015.08.002

[14] Dhakal, S., Shrestha, S., Shrestha, A., Kansal, A. and Kaneko, S. (2015) Towards a Better Water-Energy-Carbon Nexus in Cities, APN Global Change Perspectives Policy Brief No. LCD-01. Asia-Pacific Network for Global Change Research, Kobe.

[15] Waskom, R., Akhbari, M. and Grigg, N. (2014) U.S. Perspective on the Water-Energy-Food Nexus. Colorado Water Institute, University of California, Davis.

[16] Hussien, W.A., Memon, F.A. and Savic, D.-A. (2017) An Integrated Model to Evaluate Water-Energy-Food Nexus at a Household Scale. Environmental Modelling \& Software, 93, 366-380. https://doi.org/10.1016/j.envsoft.2017.03.034

[17] Copeland, C. and Carter, N.-T. (2017) Energy-Water Nexus: The Water Sector's Energy Use. Congressional Research Service, Washington DC.

[18] Fang, D. and Chen, B. (2017) Linkage Analysis for the Water-Energy Nexus of City. 
Applied Energy, 189, 770-779. https://doi.org/10.1016/j.apenergy.2016.04.020

[19] Taniguchi, M., Masuhara, N. and Burnett, K. (2017) Water, Energy, and Food Security in the Asia Pacific Region. Journal of Hydrology: Regional Studies, 11, 9-19. https://doi.org/10.1016/j.ejrh.2015.11.005 